J. Clin. Chem. Clin. Biochem.

Vol. 24, 1986, pp. 89-96

(C) 1986 Walter de Gruyter \& Co. Berlin - New York

\title{
Ascorbate Interference in the Estimation of Urinary Glucose by Test Strips
}

\author{
By B. Berg \\ Clinical Chemical Laboratory, Central Hospital, Kristianstad, Sweden
}

(Received July $1 /$ September 19,1985 )

Summary: Currently used test strip methods for the detection of glucose in urine are influenced by ascorbate and may thus give false negative results, e.g. in screening for diabetes. Six different test strips for urine glucose were evaluated for interference by ascorbate in vitro.

Interference by ascorbate varied markedly, being highest at low glucose concentrations. Interference coefficients for the individual tests were calculated to serve as an approximate index of interference by ascorbate. A new test (BM 33.071, Boehringer Mannheim GmbH, currently used in Combur-9-Test ${ }^{\circledR} /$ Chemstrip $^{\text {TM }}{ }_{-9}$ and other multiple test strips of Boehringer Mannheim) was clearly much less influenced as no urine containing $5.5 \mathrm{mmol} / 1$ glucose was read as negative even at very high ascorbate concentration. Readability of test strips differed due to patchy colour reactions. Precision was good within-test strip and within-urine but markedly less between urines.

\section{Interferenz von Ascorbat beim Nachweis von Glucose im Harn mit Teststreifen}

Zusammenfassung: Gegenwärtig benutzte Teststreifen-Methoden für den Nachweis von Glucose im Harn werden durch Ascorbat beeinflußt und können deshalb falsch negative Resultate ergeben, z. B. beim Screening auf Diabetes. Sechs verschiedene Teststreifen für Glucose im Harn wurden hinsichtlich der Interferenz durch Ascorbat in vitro geprüft. Die Interferenz durch Ascorbat variierte deutlich, sie war am stärksten bei geringen Glucosekonzentrationen. Für die einzelnen Tests wurden als Näherungs-Maß der Interferenz durch Ascorbat Interferenz-Koeffizienten berechnet. Ein neuer Test (BM 33.071; Boehringer Mannheim GmbH, z. B. enthalten im Combur-9-Test ${ }^{\circledR} /$ Chemstrip $^{\text {TM }}{ }_{-9}$ und anderen Mehrfach-Teststreifen von Boehringer Mannheim) wurde deutlich geringer beeinflußt: Kein Harn, der 5,5 mmol/1 Glucose enthielt, ergab auch bei sehr hoher AscorbatKonzentration ein negatives Testresultat. Die Ablesbarkeit der Teștstreifen differierte aufgrund von scheckigen Farbreaktionen. Die Präzision der Untersuchung mit dem einzelnen Teststreifen und dem einzelnen Harn war gut, mit verschiedenen Harnen jedoch deutlich geringer.

\section{Introduction}

Currently used test strips for the detection of glucose in urine are all based on the glucose oxidase/peroxidase detection principle. The last step in these redox reactions is more or less influenced by ascorbate in all test strips.
The problem is well documented by experiments in vitro $(1-3)$. Many efforts have been made to avoid it, e. g. by ion exchange chromatography (4), but these methods have not been widely used due to their impracticability. 
Since 1977 test strips have been available that are supplemented by a test field for reducing components in urine, in order to indicate possible interference with the glucose test. Specimens with a positive ascorbate reaction are then discarded to avoid potentially falsenegative results. However, the patient must then return to the laboratory to repeat the determination with ascorbate-free urine.

Recently a new urine test (BM 33.071, Boehringer Mannheim $\mathrm{GmbH}$ ) has been developed which contains iodate. This oxidizing agent diminishes the interfering effect of ascorbate and other reducing substances.

The aims of this study were to evaluate ascorbate interference and ease of handling of six different urine glucose test strips.

\section{Materials and Methods}

Thirty urine specimens with ascorbate concentrations below $0.1 \mathrm{mmol} / 1$ were obtained from non-diabetic patients in primary health care. The urines were spiked with glucose and ascorbate to result in glucose concentrations of $2.8,5.6,16.7 \mathrm{mmol} / 1$ ( 50 , $100,300 \mathrm{mg} / \mathrm{dl}$ ) and ascorbate concentrations of native, 0.6 , $1.1,1.7,2.3,4.5 \mathrm{mmol} / 1(100,200,300,400,800 \mathrm{mg} / \mathrm{l})$.

In this way $540(30 \times 3 \times 6)$ urine samples were examined by each test.
Four urines spiked with glucose were also tested with glutathione and gentisic acid $(0.6$ and $2.4 \mathrm{mmol} / \mathrm{l})$ and also with ascorbate up to $23 \mathrm{mmol} / \mathrm{l}$.

In table 1 the six urine glucose tests are listed by manufacturers' code names, batch number, minimum time to expiration date, nominal glucose concentration for each colour block, indicators, reaction colours and reading times. The manufacturers give little or no detailed written instructions for the performance of the test reading. The readings were therefore taken to the nearest half colour block (arbitrary unit, arb unit) from 0 ("negative"/"normal") to 3 or 4 (highest concentration) with interpolation to at least one intermediate step between the printed colour blocks. All readings lower than 0.5 unit were read as 0 arbitrary units, even if a faint reaction colour was seen.

Irregularities in the test field colours and difficulties in reading were noted.

According to the manufacturers' instructions, the test strips $C$, $\mathrm{E}$ and $\mathrm{F}$ should be read at 30-60 seconds, the former being recommended. All calculations made on the influence of ascorbic acid on the glucose estimation were based on the values recorded after 30 seconds. For 14 urines, 30- and 60-secondsreadings were compared. All test strips had at least 7 months to expiration date.

In urine specimens $1-10$, the users knew the spiked concentrations of glucose and ascorbic acid (i. e. open reading). All samples from urine specimens $11-30$ were randomised before testing (blind reading).

Six experienced readers with normal colour vision read the test strips in a room well lit with "daylight" fluorescent tubes $(5500 \mathrm{~K})$. Within each of the 30 urines, each type of test strip was read by only one reader.

Ascorbate was measured as reducing capacity (Ferrozine detection of $\left.\mathrm{Fe}^{3+} \rightarrow \mathrm{Fe}^{2+}\right)(5)$, and glucose with a glucose dehydrogenase (Merck, West Germany) method.

Tab. 1. Urine glucose tests.

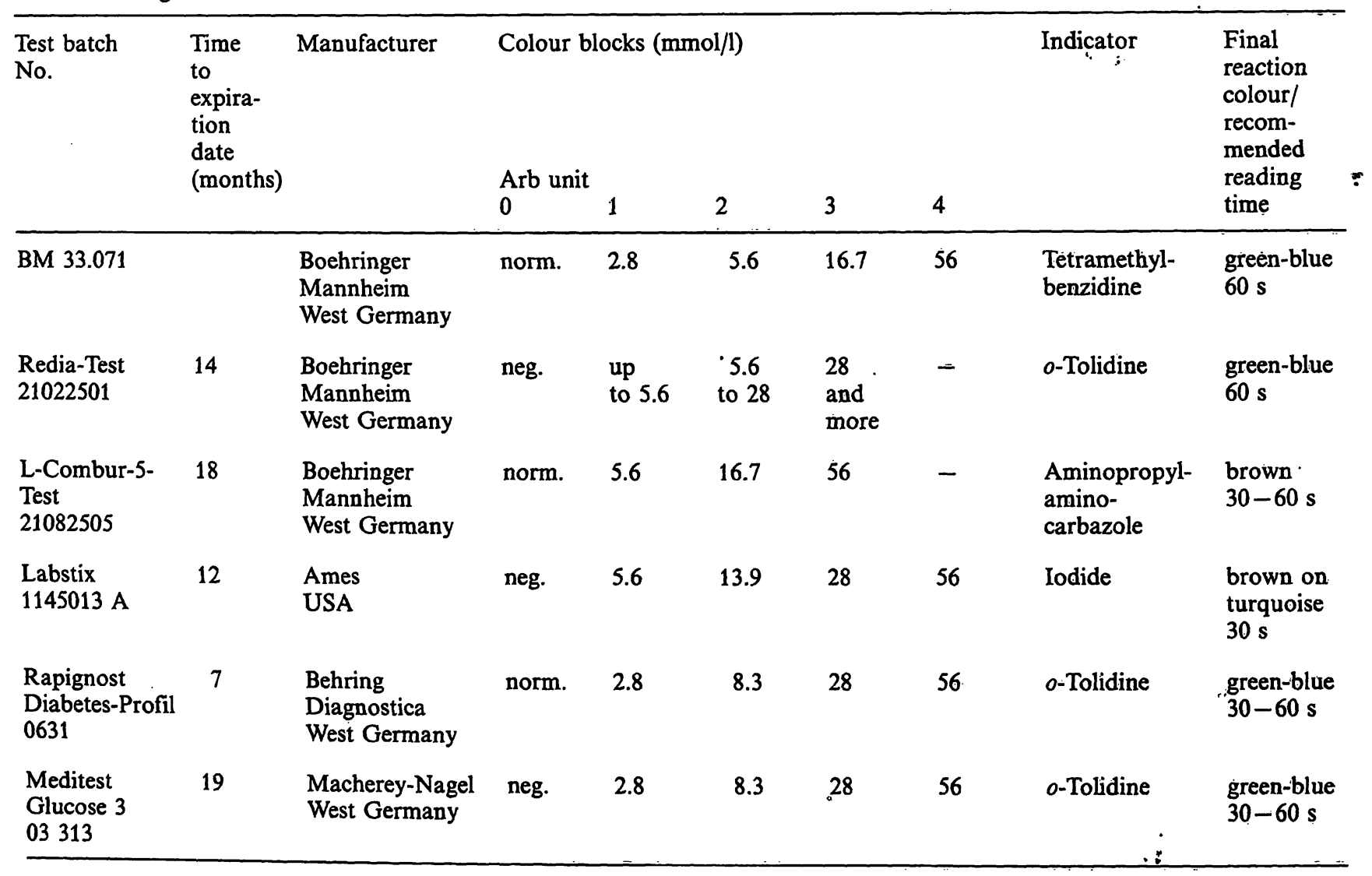




\section{Interference coefficients}

To obtain a practical index, ascorbate interference was expressed as interference coefficient ( $C$. $A$. Carstensen, to be published), derived from the intervals where interference was seen, i. e. when the estimate was significantly lower than the one with the native urine. The interference coefficient is identical with the slope $b$ in the linear regression function described below. For each glucose concentration the median readings in arbitrary units were plotted on the ordinate versus the ascorbate concentration on the abscissa. At low ascorbate concentrations, readings were reasonably linear. For this linear range, the regression coefficients were calculated for each glucose concentration:

$y=a+b x$ where

$y=$ median reading (expressed in arbitrary units)

$a=$ intercept, $i$. e. reading of glucose in urine without added ascorbate

$\mathrm{b}=$ interference coefficient

$\mathrm{x}=$ ascorbate concentration (mmol/l)

The calculated interference coefficient is only valid within the linear range of the estimated glucose concentration. The lower the interference by ascorbate, i. e. the less deviation from the expected reading, the smaller will be the absolute value of the interference coefficient. If the coefficient is $b=-1$, then the testfield reaction at a glucose concentration of one arbitrary unit is completely suppressed by $1 \mathrm{mmol} / 1$ ascorbate, $i$. e. a false negative reading is obtained. With $b=-0.5$, an ascorbate concentration of $2 \mathrm{mmol} / \mathrm{l}$ is necessary to give a reading of 0 arbitrary units. With $b=0$, the " $y$ " value will be identical to the " $a$ " intercept and constant over the entire range of ascorbate concentrations, i.e. there is no influence of ascorbate on the glucose estimation.

\section{Results}

\section{Urine glucose determination}

Little difference was found between the median results for each ascorbate glucose combination whether the reading was open or blind. Therefore, the results from all 30 urine specimens were pooled.

Figures $1 \mathrm{a}-\mathrm{f}$ show the influence of the ascorbate concentration on the reading, when the results from 30 urine specimens were plotted as medians and $10-90$ percentile confidence intervals. With increasing ascorbate concentrations, the readings decreased for all urine glucose tests.

At a glucose concentration of $2.8 \mathrm{mmol} / 1$ the decrease was often linear up to $1.1 \mathrm{mmol} / \mathrm{l}$ ascorbate. At higher glucose concentrations, the linear range extended to $2.3 \mathrm{mmol} / 1$ ascorbate. Interference coefficients are presented in table 2.

It follows from figures $1 \mathrm{a}-\mathrm{f}$ (visually) and from table 2 (numerically) that the ascorbate interference with a glucose test was much more pronounced at lower than at higher glucose concentrations. The test strips varied widely in their sensitivity to ascorbate interference. Test strip A was clearly less influenced than the other tests. Four of the test strips gave false negative median readings (i. e. 0 arb unit) at a glucose concentration of $2.8 \mathrm{mmol} / \mathrm{l}$ and $\geqslant 1.1 \mathrm{mmol} / 1$ ascorbate (tab. 3).

Even when colour was still produced at higher glucose concentrations, ascorbate still affected precision. Diagrams $2 \mathrm{a}-\mathrm{f}$ show the frequency of the readings (in arbitrary units) at a glucose concentration of 16.7 $\mathrm{mmol} / \mathrm{l}$. Regardless of the actual ascorbate concentration all values for the 30 urines were plotted. If the readings are precise and the test insensitive to ascorbate, then the distribution will be narrow. A symmetric, Gaussian distribution may be expected at absolute insensitivity. If the readings are decreased by ascorbate, the distribution will be skewed to the left.

This was observed with all tests. However, the reproducibility of test strip A (BM 33.071) was distinctly better than that of the others.

An interference with the glucose reaction, similar to that caused by ascorbate, was also caused by gentisic acid and, to a much lesser extent, by glutathione. These substances produced a colour markedly different from that of the printed colour blocks for test strips $B$ and $E$.

\section{Handling}

The glucose test strips also differed in readability and ease of handling.

For test strips $\mathrm{E}$ and $\mathrm{F}$ readability decreased strongly with urine specimens containing ascorbate, due to a patchy, flaming appearance of the colour of the test fields (tab. 4).

Sometimes the edge of the test fields had a darker or lighter colour than the center ( $E$ and $F)$. This was sometimes caused by overflow of chemicals from the adjacent test fields (for test strip F). Sometimes the whole test area showed irregular darker and brighter areas (especially for E and F). All readers had some difficulty with test strip $D$ at glucose concentrations between 5.6 and $13.9 \mathrm{mmol} / \mathrm{l}$ due to a marked speckled appearance of brown dots on turquoise background, which was not illustrated on the printed colour block.

All six readers individually chose strips $A$ and $B$ (BM 33.071 and Rediatest) as the strips easiest to read, i. e. with the lowest frequency of reading problems. 

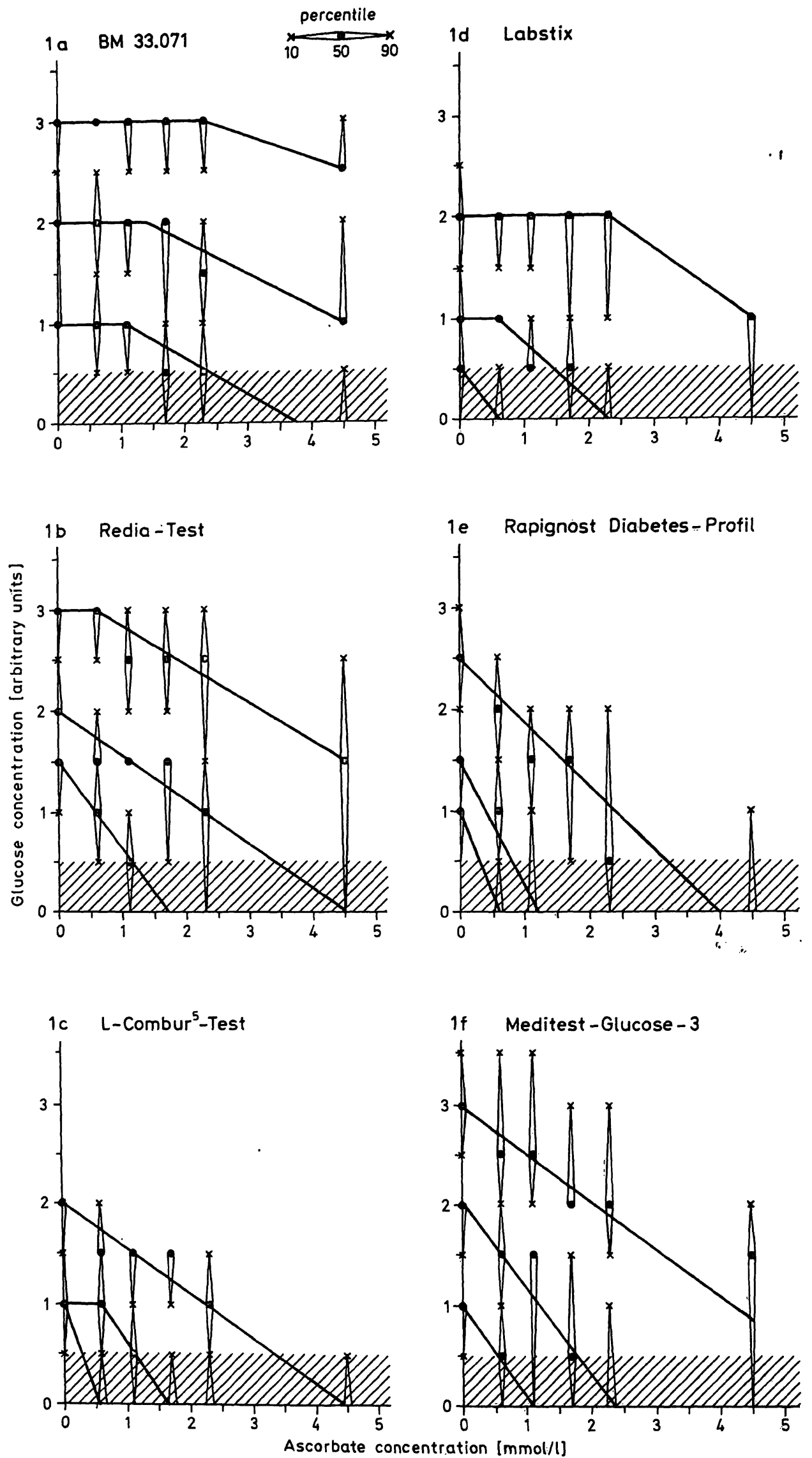

Fig. $1 \mathrm{a}-\mathrm{f}$. Influence of ascorbate concentration on urine glucose estimation with test strips at three concentrations of glucose $(16.7,5.6$ and $2.8 \mathrm{mmol} / \mathrm{l})$.

Abscissa: Ascorbate concentration (mmol/1)

Ordinate: 10th, 50th and 90th percentile for readings (arbitrary units) 
Tab. 2. Interference coefficients for six urine glucose tests at three glucose concentrations.

\begin{tabular}{|c|c|c|c|c|c|c|}
\hline & \multicolumn{6}{|c|}{ Concentration of glucose in urine } \\
\hline & \multicolumn{2}{|c|}{$2.8 \mathrm{mmol} / 1$} & \multicolumn{2}{|c|}{$5.6 \mathrm{mmol} / 1$} & \multicolumn{2}{|c|}{$16.7 \mathrm{mmol} / \mathrm{l}$} \\
\hline & $\begin{array}{l}\text { const.* } \\
\text { to } \\
\text { ascorbic } \\
\text { acid } \\
\text { (mmol/l) }\end{array}$ & $\begin{array}{l}\text { Interference } \\
\text { coefficient }\end{array}$ & $\begin{array}{l}\text { const.* } \\
\text { to } \\
\text { ascorbic } \\
\text { acid } \\
(\mathrm{mmol} / \mathrm{l})\end{array}$ & $\begin{array}{l}\text { Interference } \\
\text { coefficient }\end{array}$ & $\begin{array}{l}\text { const.* } \\
\text { to } \\
\text { ascorbic } \\
\text { acid } \\
(\mathrm{mmol} / \mathrm{l})\end{array}$ & $\begin{array}{l}\text { Interference } \\
\text { coefficient }\end{array}$ \\
\hline $\begin{array}{l}\text { BM } 33.071 \\
\text { Redia-Test } \\
\text { L-Combur-Test } \\
\text { Labstix } \\
\text { Rapignost Diabetes-Profil } \\
\text { Meditest Glucose } 3\end{array}$ & $\begin{array}{l}1.1 \\
- \\
- \\
-\end{array}$ & $\begin{array}{l}-0.258 \\
-0.892 \\
-0.907 \\
-0.833 \\
-1.667 \\
-0.833\end{array}$ & $\begin{array}{l}1.7 \\
\overline{0.6} \\
0.6 \\
- \\
-\end{array}$ & $\begin{array}{l}-0.322 \\
-0.423 \\
-0.907 \\
-0.833 \\
-1.346 \\
-0.883\end{array}$ & $\begin{array}{l}2.3 \\
0.6 \\
- \\
2.3 \\
- \\
-\end{array}$ & $\begin{array}{l}-0.227 \\
-0.346 \\
-0.423 \\
-0.455 \\
-0.557 \\
-0.312\end{array}$ \\
\hline
\end{tabular}

Correlation coefficient $r>0.95$

* const. $=$ no influence on the median glucose estimation by ascorbate up to concentrations noted in the table.

Tab. 3. Frequency of false-negative readings ( $<0.5$ arb units) in 30 urines spiked with glucose and ascorbate.

\begin{tabular}{|c|c|c|c|c|c|}
\hline BM 33.071 & Rediatest & Combur-Test & Labstix & $\begin{array}{l}\text { Rapignost } \\
\text { Diabetes- } \\
\text { Profil }\end{array}$ & $\begin{array}{l}\text { Meditest } \\
\text { Glucose-3 }\end{array}$ \\
\hline
\end{tabular}

Glucose $2.8 \mathrm{mmol} / \mathrm{l}$

Ascorbate concentration (mmol/l)

$\begin{array}{rr}0 & 0 \\ 6 & 9 \\ 11 & 12 \\ 23 & 29 \\ 25 & 29 \\ 29 & 30\end{array}$

0
19
29
30
30
30

3
19
27
30
30
30

$\begin{array}{rr}0 & 1 \\ 24 & 10 \\ 30 & 28 \\ 30 & 30 \\ 30 & 30 \\ 30 & 30\end{array}$

Glucose $5.5 \mathrm{mmol} / \mathrm{l}$

Ascorbate concentration (mmol/l)

0
1
3
17
27
30

0
0
1
13
22
30

$\begin{array}{rr}0 & 0 \\ 2 & 2 \\ 10 & 3 \\ 30 & 6 \\ 30 & 19 \\ 30 & 30\end{array}$

Glucose $16.7 \mathrm{mmol} / \mathrm{l}$

Ascorbate concentration (mmol/l)

\begin{tabular}{lllllll}
0 & 0 & 0 & 0 & 0 & 0 & 0 \\
0.6 & 0 & 0 & 0 & 0 & 0 & 0 \\
1.1 & 0 & 0 & 0 & 0 & 0 & 0 \\
1.7 & 0 & 0 & 0 & 0 & 5 & 0 \\
2.3 & 0 & 0 & 1 & 0 & 3 & 3 \\
4.5 & 0 & 4 & 20 & 3 & 23 & 3 \\
\hline
\end{tabular}

For most urines, increasing the ascorbate concentrations gave a progressive decrease in the readings without much irregular scattering. This was seen in both the open and the blind trials (number of irregularities: $\geqslant 0.5$ arb unit corresponds to 2 out of 150 and 19 out of 300 possible combinations; 1 arb unit corresponds to 1 out of 150 and 1 out of 300). Thus, the combination of one reader, one test strip and one urine specimen had a rather high degree of precision even when the readings were taken blind.

Median readings at 60 seconds were distinctly higher than at 30 seconds for test strips C, E and F. Especially at high glucose concentrations, the increase amounted to 1 arb unit for test strips $E$ and $F$. 

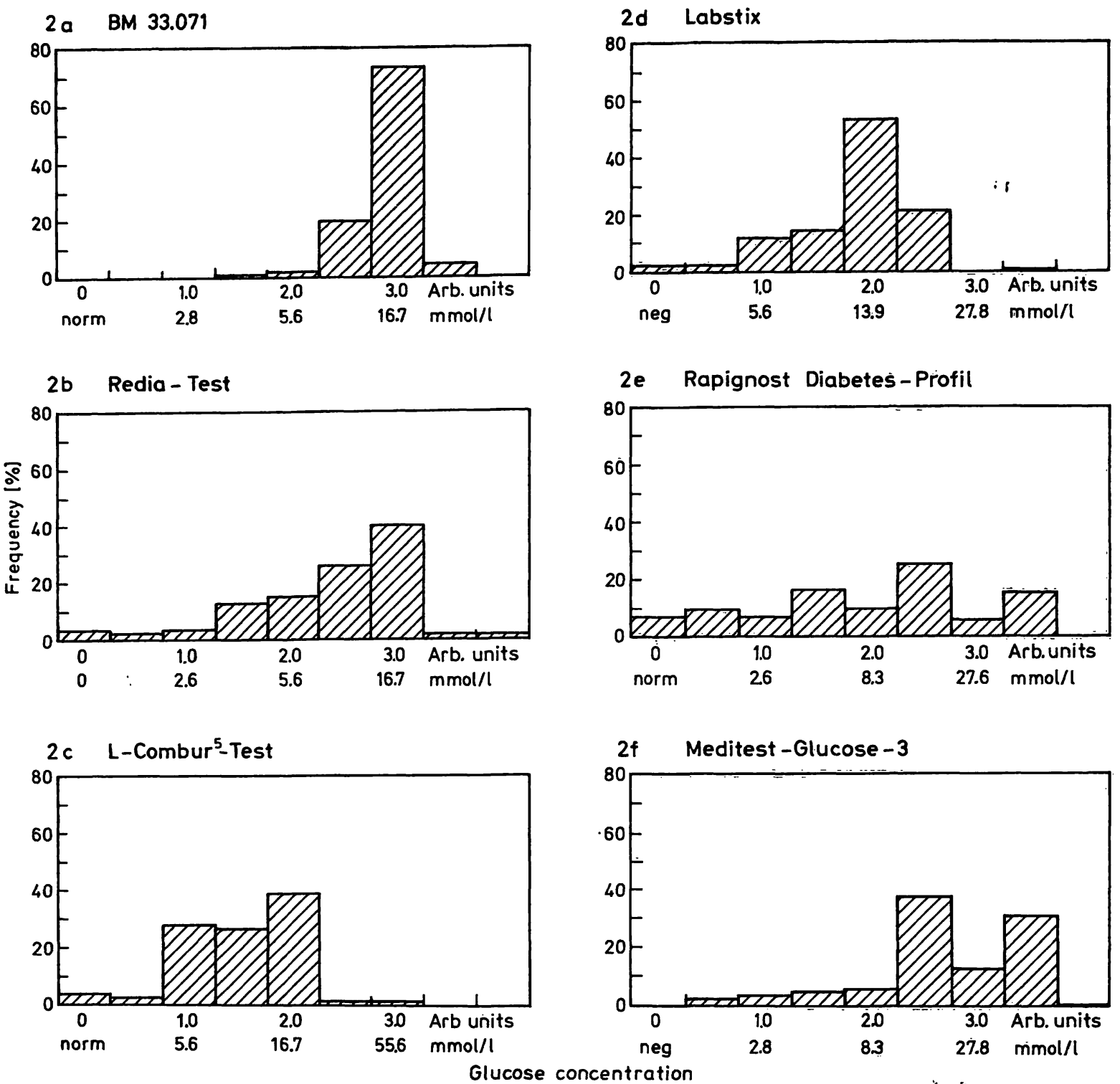

Fig. $2 \mathrm{a}-\mathrm{f}$. Frequency of test strip readings at a urine glucose concentration of $16.7 \mathrm{mmol} / \mathrm{l}$. All readings were pooled without respect to ascorbate concentration.

Abscissa: Reading results (arbitrary units and corresponding nominal glucose concentration)

Ordinate: Frequency of readings

Tab. 4. Problems in reading the test fields (540 urine samples each).

\begin{tabular}{llll}
\hline $\begin{array}{l}\text { Test } \\
\text { strip }\end{array}$ & $\begin{array}{l}\text { Colour } \\
\text { interpretation } \\
\text { difficult }\end{array}$ & $\begin{array}{l}\text { Flaming } \\
\text { appearance } \\
\text { of test fields }\end{array}$ & $\begin{array}{l}\text { Deviating } \\
\text { colour of test } \\
\text { field edge }\end{array}$ \\
\hline A & $19(1)$ & 13 & 1 \\
B & $17(7)$ & 7 & $2(1)$ \\
C & 16 & $14(1)$ & 1 \\
D & $66(37)$ & $37(1)$ & 4 \\
E & $76(35)$ & $116(84)$ & $28(15)$ \\
F & $39(14)$ & $76(41)$ & $32(12)$ \\
\hline
\end{tabular}

Figures within brackets denote urines where the reaction was classified as $<0.5$ arb unit. Reading problems only relate to test fields with positive readings (i. e. often for less than 540 urine samples).

\section{Discussion}

Numerous in vitro experiments have clearly demonstrated that reducing substances interfere with urine test strips that use redox reactions for the detection of glucose and haemoglobin $(1-3,6)$. Ascorbate is the most important reducing substance, although interference by urate, glutathione and gentisic acid may possibly occur (6). In fact, in many years of routine clinical experience with native patient urines, we have never seen the aberrant reaction colours caused by gentisic acid and glutathione described here for test strips B and E. Therefore, these substances lack clinical significance for urine glucose tèsting. 
On the basis that ascorbate may cause false negative glucose results, at least one test strip manufacturer has recommended that ascorbate-containing urine specimens should be discarded and a new specimen obtained. Another way to circumvent the problem has been to discourage patients to eat fruits, vegetables and vitamin supplements prior to assay. However, modern test strips should be applicable in a simple way to random urine specimens.

Exchange chromatography (4) or ascorbate oxidase pretreatment ( $B$. Berg, to be published) have been employed to eliminate ascorbate. Unfortunately, little attention has been given to the heart of the problem, i. e. the unavailablility of ascorbate-insensitive strip tests for glucose.

The six test strips for urine glucose evaluated here differed markedly in their sensitivity to ascorbate. It should be mentioned that one of the two strips containing test fields for ascorbate also had the highest sensitivity to interference.

The new Boehringer Mannheim concept of including iodate in the test field appears to be effective. Iodate oxidizes ascorbate to non-interfering dehydroascorbate, without affecting the indicator reaction.

Ascorbate affects test results in three modes:

a) lower precision at all glucose concentrations (tab. 2)

b) false-negative results

c) compromised readability due to uneven distribution of the reaction colour on the test field. This may be caused by chromatographic effects: If urine is absorbed into the test field paper mainly from the edges less ascorbate will reach the middle of the test area. On the other hand, reading difficulties were also observed with native unspiked urines (tab. 4).

The interference coefficients give an approximate numerical expression of the sensitivity to ascorbate interference by allowing an estimation of the ascorbate concentration at which a false negative result will be obtained. Naturally, interference coefficients may also be calculated using absolute glucose concentrations in order to "standardize" arbitrary units obtained with different test strips. However, not all test strips have nominal levels for absolute concentrations.

As might be expected, low levels of glucose were more easily falsified than high levels. In Scandinavia, urine glucose tests for diabetes screening are expected to have a very high sensitivity with little emphasis on quantification. Thus, screening for early, mild diabetes with only low-grade glucosuria will be more severely affected than monitoring of known diabetes with high glucosuria.

Different manufacturers recommend different cut-off limits for diabetes screening, e. g. $2.8-5.5 \mathrm{mmol} / \mathrm{l}$ glucose. Only evaluations in clinical practice can decide which level is the most suitable.

In any case, the cut-off limits should be correctly reflected by the screening test without interference, e. g. from ascorbate.

The new test BM 33.071 (Boehringer Mannheim $\mathrm{GmbH}$ ) was not completely insensitive to ascorbate but still had a wide safety margin. At a urine glucose concentration of $5.5 \mathrm{mmol} / \mathrm{l}$, even $23 \mathrm{mmol} / \mathrm{l}$ ascorbate failed to completely abolish the reaction. Since the levels of ascorbate in urine do not always increase proportionately to the amount of vitamin $\mathrm{C}$ ingested this level is far higher than encountered in clinical practice. According to Angel et al., urinary ascorbate did not exceed $5 \mathrm{mmol} / \mathrm{l}$ even after intake of $5 \mathrm{~g}$ ascorbic acid per day for several weeks (7).

In our patient population in Kristianstad county ascorbate concentrations of 0.6 to $1.2 \mathrm{mmol} / \mathrm{l}(100-200$ $\mathrm{mg} / \mathrm{l}$ ) are typically seen in 3 to $20 \%$ of the urine specimens. Higher concentrations are very rare. Therefore, it is probably sufficient for a test strip to tolerate $2 \mathrm{mmol} / \mathrm{l}$ ascorbate. But even at such low levels several of the test strips were markedly affected.

In this study even well trained readers found marked differences in the ease of handling of the test strips. Difficulties in comparing the test strip with the printed colour blocks on the bottle were highly correlated with an uneven distribution of the reaction colour on the test field.

Even when a test strip is completely immersed into the urine specimen, urine may not always be distributed evenly throughout the test paper. This may explain the patchy, flaming or dotted appearance of the test fields, especially observed with the strips E, F (sporadic error) and $D$ (systematic error). The problem is enhanced if the colour block does not accurately reflect the colour reaction of the test strip. This may cause severe reading problems not only for glucose tests.

Even in the blind readings, each observer achieved high within-reader in within-test strip precision. However, between-urine and between-reader variation was considerable. Thus, matrix effects on test strip function may be a major part of analytical imprecision, in addition to reader subjectivity and varying light conditions (8). 
As expected for a non-equilibrium reaction such as the redox test used here, the reaction colour varied markedly with incubation time (up to 1 arb unit for an extra incubation time of 30 seconds). For qualitative tests, this is a minor limitation. However, if a test is labeled "semiquantitative", a defined reading time should be used. It is not sufficient to use the wide recommendations by the manufacturers (e. g. $30-60 s$ ).

Unfortunately, in published evaluations of test strip performance, little attention has been given to the specification of detailed reading instructions. The manufacturers have usually omitted to give exact instructions on how to interpolate and round off the test field readings, i. e. whether to use the nearest colour block, go upwards or go downwards. This is important as it means $0.5-1$ arb units (i. e. colour block) difference in the result.

It is not enough for the manufacturer to develop a test strip that produces a colour change in the presence of an analyte. Every test should also be evaluated for ease of handling and clinical usefulness. Test strips are often used by untrained personell, having more difficulties in reading than the experienced readers in this study.

\section{Acknowledgement}

I thank Boehringer Mannheim, West Germany, for supplying all test strips used.

\section{References}

1. Appel, W., Nuerck, C. \& Merkle, U. (1979) Medical Laboratory $6,29-39$.

2. Daae, L. N. W. \& Juell, A. (1983) Scand. J. Clin. Lab. Invest. 43, 747-749.

3. Kutter, D. (1983) Schnelltests in der klinischen Diagnostik. Urban \& Schwarzenberg, München - Wien-Baltimore, pp. 28-39.

4. Brandt, R., Guyer, K. E. \& Banks, W. L. (1974) Clin. Chim. Acta 51, 103-104.

5. Butts, W. C. \& Mulvihill, H. J. (1975) Clin. Chem. 21, 1493-1497.

6. Feldman, J. M., Kelley, W. N. \& Lebowitz, H. E. (1970) Diabetes 19, 337-343.

7. Angel, J., Alfred, B., Leichter, J., Lee, M. \& Marchant, L. (1975) Internat. J. Vit. Nutr. Res. 45, 237-243.

8. Dyrberg, J., Pedersen, L. \& Aagaard, O. (1976) Clin. Chem. $22,205-210$.

Bertel Berg

Clin. Chem. Lab.

Central Hospital

S-291 85 Kristianstad 